\title{
A CONCEPÇÃO DE OBESIDADE E PADRÃO CORPORAL POR MEDIAÇÕES IDEOLÓGICAS DA MÍDIA
}

\author{
Mayra Fernanda Vendruscolo \\ Escola Estadual Pedro Mendes Fontoura, Coxim, Mato Grosso do Sul, Brasil \\ André Malina \\ Universidade Federal do Rio de Janeiro, Rio de Janeiro, Rio de Janeiro, Brasil \\ Ângela Celeste Barreto de Azevedo \\ Universidade Federal do Rio de Janeiro, Rio de Janeiro, Rio de Janeiro, Brasil
}

\begin{abstract}
Resumo
A obesidade em contraste ao estabelecimento de um padrão corporal é uma questão social atual, discutida, entre outras, na área de Educação Física. Na presente pesquisa verificou-se como é veiculada essa questão da obesidade e do padrão corporal pela mídia, relacionados aos elementos ideológicos contidos na sociedade de consumo. Para análise, foram escolhidas reportagens do período de um ano de uma revista com tiragem semanal superior a um milhão de exemplares. Os resultados demonstraram que a mídia pode influenciar uma concepção da obesidade e padrão corporal como um fim em si mesma, responsabilizando o indivíduo por meio da mediação ideológica. Nesse sentido, confunde-se saúde, beleza e lucro, atrelando consumismo de produtos à busca de um corpo perfeito e padronizado socialmente.
\end{abstract}

Palavras chave: Obesidade. Comportamento Social. Mídia.

\section{Introdução}

No decorrer da história da humanidade, por vezes, ter o corpo com formas arredondadas e proeminentes estava associado à beleza. Atualmente, ser magro tornou-se sinônimo de beleza e saúde. De fato, no que se refere genericamente à saúde, a obesidade aumenta os riscos de desenvolverem-se doenças crônicas em diferentes idades, como o diabetes mellitus tipo 2, a hipercolesterolemia (nível de colesterol acima do normal no sangue), a hipertensão arterial, doenças cardiovasculares, apnéia do sono, problemas psicossociais, doenças ortopédicas e diversos tipos de câncer (OMS, 2006).

Nesse contexto, a cadeia produtiva relacionada à obesidade e, de forma associada, às questões como o culto ao corpo belo, as dietas e a estética, movimentam bilhões de dólares. $\mathrm{O}$ assunto ganha destaque nos meios de comunicação de massa e é tratado de diversas formas, estimulando tanto a venda de produtos cosméticos e alimentícios 
oferecidos pela indústria de consumo, como a definição de um padrão estético. E, assim, o papel assumido pela mídia amplia-se, sendo esta considerada um agente formador de opinião e criador-reprodutor de cultura. (FELIPPE et al, 2004).

$\mathrm{Na}$ perspectiva de uma análise sociológica referente à obesidade, é pressuposto que ocorra uma interpretação da realidade desconsiderando fatores importantes, dissociados do cotidiano aos quais as pessoas estão submetidas. Segundo Bagrichevsy e Palma (2004), devem ser considerados fatores como: distribuição desigual de renda; nível de emprego e desemprego; condições sanitárias básicas; condições de moradia e alimentação; (in)disponibilidade de tempo livre; acesso aos serviços de saúde e escolaridade.

No presente estudo buscamos verificar o discurso ideológico contido em reportagens da revista Veja, relacionando questões da obesidade com a beleza, com o culto ao corpo e com o consumo. A escolha desta revista é dada pela representatividade que expressa na mídia impressa brasileira, sendo considerada a revista de maior circulação nacional, com uma tiragem semanal de mais de um milhão de exemplares há muitos anos.

Dentre os objetivos propostos, cabe compreender e desvelar valores e conceitos presentes nos discursos veiculados na revista com cotejo à relação indivíduo e sociedade, na questão da obesidade e padrão corporal. Buscamos investigar se, e como a revista Veja acaba por interferir nas relações sociais a partir do pressuposto de que o culto ao corpo tem uma base material concreta que dá sustentação ao discurso hegemônico de um corpo magro e saudável. Dessa forma, a perspectiva é de ampliar o debate sobre a influência da mídia na formação de nossos hábitos.

\section{Metodologia}

A pesquisa se caracteriza como sendo de caráter qualitativo, com abordagem exploratória e descritiva (GIL, 2008). A coleta das informações consistiu em pesquisar, no período de um ano, como a questão da obesidade e padrão corporal estava sendo veiculada nas reportagens da revista Veja.

Para tanto, foram selecionadas de forma aleatória oito edições da referida revista, equivalentes a oito semanas, publicadas durante o ano de 2010. Selecionamos para análise nessas revistas, além de todas as reportagens trazidas relacionadas às questões da obesidade, beleza e o culto ao corpo, um anúncio sobre alimentos que expressa um discurso ideológico diante do contexto da sociedade capitalista.

Após a coleta, realizou-se a análise do material escrito, objetivando identificar o significado do discurso ideológico contido nos textos e imagens selecionados referentes ao corpo e obesidade. O desenho teórico-metodológico escolhido foi o de atribuir centralidade de análise à categoria Ideologia, entendendo-a como fundamental para a compreensão da sociedade e, em especial, da mídia. Como referencial teórico de análise foram adotados como fonte principal Karl Marx e Friedrich Engels, autores da obra "A Ideologia Alemã".

Pensar a Prática, Goiânia, v. 17, n. 2, p. 503-516, jan./mar. 2014 
De acordo com esses autores, a produção das ideias está diretamente ligada à atividade material, à vida real, pois os homens são o que as suas condições de vida lhes permitem que sejam. Assim, a maneira como pensam e agem esses homens está diretamente ligada a uma ideologia responsável por orientar esses pensamentos conforme o tempo-histórico nos quais estão inseridos. (MARX e ENGELS, 2007).

Por isso, a ideologia é muitas vezes chamada por Marx de uma ilusão, distorção ou falsa consciência da realidade vivida. Sabe-se que, ao longo do tempo, o corpo foi sendo desvelado, e cada vez mais o homem foi conhecendo e tomando poder sobre o próprio corpo. A realidade social, no entanto, é uma dos fatores que determinam que corpo é esse, que ganhou diferentes sentidos e significados no decorrer da história. Assim, o conceito do corpo "perfeito" que temos hoje, é produto de uma construção sócio-histórica, atualmente reverberada pela mídia, que pode nos influenciar sobre como pensamos.

\section{Corpo, obesidade e beleza}

A fantasia de que só basta querer para adquirir a imagem corporal desejada está associada ao avanço da tecnologia da beleza. $\mathrm{O}$ apelo midiático seduz e fascina a alcançar um corpo perfeito. Com a intenção de impulsionar o lucrativo mercado da indústria da magreza, sem se preocupar com riscos que podem trazer às pessoas, matérias apontam que a pessoa é obesa apenas por uma questão de "gula", "desleixo" ou "preguiça" (FELIPPE et al, 2004). O corpo tem sido transformado em mercadoria de consumo, sendo a pessoa desportiva, sadia, bela e forte uma criação recente dessa mecanização (PILLATI, 2007). Já o corpo obeso é discriminado e excluído socialmente.

A indústria da estética movimenta bilhões de dólares. O assunto ganha destaque nos meios de comunicação de massa, que tratam o problema das mais diversas formas, estimulando tanto a venda de produtos alimentícios oferecidos pela indústria de consumo, como a definição de um padrão estético corporal. Desta forma, a mídia influencia na direção e organização da vida social, sendo agente formador de opinião e criadorreprodutor de cultura (FELIPPE et al, 2004). ${ }^{1}$

Jovens e adultos, homens e mulheres seguem um padrão de corpo "enxuto", "compacto", "firme", "jovem" e "musculoso" influenciado por setores organizados com interesses diversos. Para isso, vale ser "cortado", "bombado", "enxertado", "siliconado", "transformado", "disciplinado" e "educado", objetivando o "corpo perfeito". No Brasil, valorizam-se também músculos e formas amplas em localizações específicas do corpo, como os glúteos e os seios, segundo os números obtidos na maior pesquisa internacional realizada até então sobre tratamentos estéticos, divulgada pela Sociedade Internacional de Cirurgia Plástica Estética (ISAPS, 2010). As brasileiras, cada vez mais, pagam para ter

1Também em outros assuntos de interesse da Educação Física, há influência da mídia. Por exemplo: "O noticiário esportivo não só é um programa sólido, mas uma garantia de alto índice de audiência e tiragem" (SCHWIER, 2013, P. 140).

Pensar a Prática, Goiânia, v. 17, n. 2, p. 503-516, jan./mar. 2014 505 
seios e glúteos maiores, além de cintura e quadris esculpidos pela lipoaspiração, na busca do que consideram o corpo perfeito (SBCP, 2010).

O Brasil é um dos países campeões em número de cirurgias plásticas estéticas e cirurgiões plásticos qualificados, fato que reflete a relevância do corpo para a sociedade contemporânea no Brasil, e a busca pela perfeição da escultura corporal. Esta busca impulsiona uma pujante indústria da beleza (SBCP, 2010), estimulada pelos meios de comunicação que veiculam e produzem notícias, representações e expectativas nos indivíduos.

Propagandas, informações e noticiários incentivam o uso de produtos dietéticos e práticas alimentares para emagrecimento, ao mesmo tempo em que incentivam, também, contraditoriamente, o consumo de lanches tipo fast food (SERRA E SANTOS, 2003). A comunicação tem sido "o instrumento para consolidação do sistema capitalista e do processo de alienação; ela cria mitos, impõe valores, necessidades, cria a cultura a serviço e interesse do capital" (FELIPPE et.al, 2004, p.5).

A obesidade está relacionada à maneira de viver e às condições efetivas de vida e saúde de sociedades, classes, grupos e indivíduos, que são construções históricas e sociais. A responsabilidade sobre a obesidade vem sendo lançada sobre o indivíduo e torna-se dever dele adotar medidas de controle; sejam elas educacionais, comportamentais, ou farmacológicas. Mas, ainda que essas orientações possam ser importantes no âmbito individual, não serão suficientemente efetivas para a prevenção e controle da obesidade em âmbito populacional, se não estiverem associadas à medidas que contemplem as diversas dimensões físicas, econômicas, políticas e socioculturais (LESSA, 1998; SWINBURN, EGGER, RAZA, 1999).

\section{Apresentação e Discussão dos Resultados}

Veja é uma revista semanal brasileira publicada pela Editora Abril, criada em 1968 pelos jornalistas Victor Civita e Mino Carta, sendo a revista semanal de maior circulação no Brasil. Como é um meio de comunicação e, ao mesmo tempo, uma empresa privada, seu maior produto de oferta e busca de lucro, é a informação. Diferente de outros produtos que compramos, porém, a informação é acompanhada de subjetividades, ou seja, vai além da aparente neutralidade ou imparcialidade ideológica. As reportagens das edições analisadas apontam, predominantemente, uma perspectiva de padrão corporal de beleza adaptada à nossa época. Vejamos o trecho abaixo:

A atriz fluminense de 31 anos (atualmente grávida de três meses), morena e curvilínea, mede a altura certa (1,70 metro), pesa os quilos desejáveis (57) e registra a centimetragem perfeita (87 de busto, 67 de cintura, 98 de quadril) para se encaixar na preferência nacional. (MOHERDAUI E SINATURA, 2010a, P. 112).

Pensar a Prática, Goiânia, v. 17, n. 2, p. 503-516, jan./mar. 2014 506 
Inicialmente, podemos inferir que pode haver uma tendência à uniformidade dos corpos, e que a mulher deve buscar essa "centimetragem perfeita", pois esta é uma "preferência nacional". A ideologia presente induz as mulheres a adquirirem e passarem a ser representações muitas vezes distorcidas de suas condições reais de vida ou incompatíveis com suas condições biológicas individuais. Por exemplo, uma mulher baixa e com uma estrutura óssea grande, não conseguirá biologicamente ser uma mulher esguia.

Em outra reportagem, mostra-se como a beleza foi transformada em uma mercadoria de consumo. Ouvindo especialistas, as pessoas são julgadas e classificadas conforme o tipo de corpo que apresentam.

Fazemos julgamentos o tempo todo e, hoje, usamos a beleza como um indicador de competência. Pessoas com rosto simétrico ou feições mais definidas são vistas como mais dignas de confiança. (MOHERDAUI E SINATURA, 2010b, P. 138).

Nos últimos anos se popularizou que, para sermos consideradas pessoas bonitas, é necessário que sejamos magros. Os mecanismos que determinam essa condição de um padrão corporal perfeito são produzidos por um discurso ideológico que resulta em generalizações, o qual por vezes é absorvido de forma alienada através de reportagens que trazem inculcações, como: "tudo o que o obeso quer é ficar magro" (VILLAVERDE, 2010a, P. 84).

Assim, nossas crenças e verdades vinculam-se organicamente aos padrões da sociedade e da cultura na qual estamos inseridos. Atualmente, o culto ao corpo ganha destaque, desde que seja um corpo magro, com musculatura definida, "perfeito" ao padrão de beleza da sociedade de consumo. Para reforçar esse culto ao corpo, existe um processo ideológico com mecanismos de veiculação e sustentação, tais como os encontrados na revista Veja, de onde destacamos o trecho: "As medidas da gatíssima Ana Lys são de fazer morrer de inveja às mais cheinhas: 1,72 metro de altura, 48,5 quilos, 58 de cintura e 34 de calça (não, não existe no Brasil)" (MAGALHÃES, 2010, P. 85).

A preocupação com as formas do corpo, peso corporal e alimentação é crescente porque ninguém quer estar fora dos padrões de beleza. Observam-se nas reportagens das edições analisadas, especialistas ouvidos que apontam que o culto ao corpo pode delinear valores e até posição social. "Se considerarmos beleza como a capacidade de atração, são pouquíssimas as áreas em que ela não tem alguma influência - talvez no chão de fábrica" (MOHERDAUI E SINATURA, 2010b, 136).

Marx e Engels (2007) defendem que as manifestações ideológicas mais relevantes estão relacionadas com interesses de classe. Do culto ao corpo instalado na sociedade, resulta, aparentemente, que os privilegiados são as pessoas a adotar um estilo de vida "saudável", porque se trata de um interesse que as envolve diretamente: os seus corpos. Os autores apontam que a ideologia é capaz de produzir uma falsa consciência como essa.

Pensar a Prática, Goiânia, v. 17, n. 2, p. 503-516, jan./mar. 2014 507 
Sendo assim, por fatores da dinâmica do modo de produção (capitalista) em que vivemos, nos é mediada a ideia de que devemos ser pessoas magras e bonitas. Pode haver, por trás disso, no entanto, interesses de classe. Por conseguinte, para Marx e Engels (2007), a ideologia é uma forma de dominação da classe dominante ${ }^{2}$. Interesses particulares de classe, por meio da ideologia são entendidos socialmente como sendo de ordem coletiva.

Observou-se que nas reportagens aparecem dicas, produtos e serviços que se forem usufruídos ajudarão a alcançar um corpo perfeito. Verifica-se, portanto, que o corpo passou a ser alvo de investimentos e interesses, ou seja, percebeu-se como é um campo lucrativo.

Desta forma, o corpo está nos interesses de "mercados" aparentemente diversos, como os da moda, produtos cosméticos, práticas esportivas, produtos alimentícios, dentre outros. Essa busca pela aparência, que marca a vida social atual, nos ajuda a compreender a centralidade da ideologia nesse culto ao corpo da cultura contemporânea. Trata-se de uma preocupação geral que atravessa diferentes setores, classes sociais e faixas etárias da população, apoiada nos discursos da estética e da saúde. Por essa razão, o discurso ideológico se apropria, em especial, dos meios de comunicação para fortalecer a ideia de que devemos combater a obesidade em busca de saúde e beleza.

Neste contexto, diante das reportagens analisadas, produziu-se uma relação direta entre estética e saúde. Observe o que diz uma paciente que em uma das matérias conta que realizou a cirurgia de redução de estômago, e depois fez uma cirurgia plástica: "Depois que você fica magra e não tem mais do que reclamar, a cicatriz incomoda um pouco, sim. Mas não troco este corpo pelo outro de jeito nenhum" (VILLAVERDE, 2010a, P. 85). Neste caso, por exemplo, nota-se que o objetivo maior da paciente não está relacionado à saúde, mas principalmente à estética. Identifica-se que agora, magra, ela se sente satisfeita com seu corpo, mesmo com as cicatrizes que as cirurgias deixaram.

Entre as pessoas obesas há um inconformismo e a busca por um corpo belo associado à magreza, em consequência do preconceito e discriminação que sofrem. A obesidade é apresentada nas reportagens analisadas num campo de tensões para se alcançar o padrão de beleza corporal, responsabilizando o indivíduo pela obtenção desse padrão. Nesse sentido, segundo uma dessas reportagens, o indivíduo deve "praticar uma hora de atividade física diariamente, tomar café da manhã todos os dias, fazer a maior parte das refeições em casa, não sair da linha nos fins de semana e pesar-se regularmente" (MAGALHÃES, 2010, P. 84-86).

Dessa maneira, cabe responsabilizar os obesos pela sua condição e considerar que são gordos porque comem muito, não praticam exercícios e são incapazes de se controlar, tal como induz o seguinte trecho: "Nada é proibido e frequentemente ela se permite

2A classe dominante, em Marx e Engels, é também alienada dadas as características do sistema capitalista. Estamos tratando, por outro lado, da prevalência das ideias dominantes como sendo axiologicamente um valor coletivo das classes sociais indistintamente. Nosso esforço é de responder, com o recorte realizado, como isso ocorre.

Pensar a Prática, Goiânia, v. 17, n. 2, p. 503-516, jan./mar. 2014 508 
pequenos luxos, mas nunca exagera nem come por comer, naquele automatismo típico dos gordos" (MAGALHÃES, 2010, P. 88).

Daí, a obsessão pelas dietas, a compulsão pela malhação. Afinal, a escolha de ter um corpo magro resume-se em comer pouco e praticar atividades físicas, o que só depende do indivíduo. Para alguns especialistas entrevistados pela revista, "O aumento de medidas é consequência do aumento de peso da população (...) Temos dois componentes para explicar o crescimento: uma redução da atividade física e um aumento da ingestão calórica" (MOHERDAUI E SINATURA, 2010a, P. 114). Nesse sentido, pessoas que não seguem esta orientação podem ganhar ainda um estereótipo de descompromissadas e preguiçosas, principalmente se são obesas.

Como seguir tal orientação, diante do contexto em que os trabalhadores estão inseridos? A maioria sai cedo de casa e cumpre uma jornada de trabalho de 8 a 12 horas, sem descanso. Por vezes, eles almoçam no próprio trabalho ou em algum estabelecimento e acabam optando por refeições rápidas, do tipo fast food, especialmente em grandes cidades. Depois de um dia de trabalho intenso, chegam cansados às suas casas e acabam tendo que se recompor organicamente para a jornada do dia seguinte, dormindo ou vendo televisão, ou mesmo atendendo à família.

As pessoas tentam conseguir suprir uma grande demanda de atividades, mas as transformações no mundo do trabalho produziram alterações no tempo humano, e ainda contribuíram para o aparecimento de inúmeras patologias psicossociais, como stress, depressão, síndrome do pânico, fobia social etc. Isoladamente dessas questões, chama ainda atenção nas reportagens analisadas que "Além do clássico binômio dieta e atividade física, outros dois fatores têm ganhado relevância na equação da manutenção do peso: sono reparador e controle do stress" (MAGALHÃES, 2010, P. 88). Como dormir bem diante do contexto do mundo do trabalho?

Mas não é somente a classe trabalhadora mal remunerada que enfrenta o problema da obesidade: "Persuadir um executivo a trocar o sanduíche com refrigerante na frente do computador, por um peixe com legumes no restaurante da esquina tampouco é tarefa fácil" (AL-ASSAL, 2010, P. 184). Verifica-se que o discurso ideológico social propõe uma coisa, mas o sistema capitalista nos impõe outra.

A ideologia surgiu principalmente da divisão do trabalho e, consequentemente, é um produto resultante da divisão da sociedade em classes sociais. Ela atua na manutenção da alienação. Assim, Marx mostra que em toda sociedade dividida em classes, há luta pela manutenção da ordem social estabelecida e pela manutenção no poder. A ideologia atua, pois, na manutenção do poder pela alienação. (MARX e ENGELS, 2007).

Assim, ideologicamente e de forma hegemônica, ser uma pessoa obesa é sinônimo de doença e prejuízos à saúde e à economia. Do mesmo modo, praticar exercícios físicos tornou-se gerador de saúde e receita de um corpo saudável. Não estamos, neste caso, negando os estudos que evidenciam cientificamente resultados positivos alcançados para a saúde dos indivíduos que praticam exercícios físicos. Propomos aqui, no entanto, um alerta aos discursos simplistas. Ao discutir sobre a obesidade é necessário inserir o tema em um contexto sócio-histórico mais amplo - assim

Pensar a Prática, Goiânia, v. 17, n. 2, p. 503-516, jan./mar. 2014 509 
como a própria questão da saúde - o qual é resultado de diferentes formas de organização social, e não um produto que deriva de um fator isolado e individual.

O lucro, por exemplo, é um objetivo do sistema capitalista, e o consumo desenfreado é incentivado a todo o momento. Assim, todo indivíduo desperta interesse na sociedade de consumo, desde que esteja adequado à categoria de "consumidor". Podemos dizer, então, que o obeso é um "mal necessário", pois gera riqueza para muitos setores do mercado. Os obesos tornaram-se mais uma das formas de exploração da sociedade de consumo, pois são disponibilizados inúmeros produtos específicos para as pessoas obesas.

Depois da dieta, vem o maior de todos os desafios: preservar a silhueta alinhada. O segredo está na eterna vigilância: não descuidar jamais dos novos hábitos, sem transformá-los, no entanto, em uma camisa de força (MAGALHÃES, 2010, P. 82).

As reportagens apontam que um dos fatores de maior impacto para a obesidade são os comportamentos que estão ligados aos hábitos de vida da população. Desta forma, quando se trata de um indivíduo obeso, comumente ouvimos que cabe a ele mudar seus hábitos, como praticar atividades físicas, deixar de lado o sedentarismo, ter uma alimentação equilibrada, entre tantas outras sugestões; para, assim, alcançar resultados positivos.

Apesar de algumas ações governamentais estimularem e até criarem políticas públicas com interesses voltados ao incentivo à população na adoção de um estilo de vida mais saudável e ativo, sabemos que, ainda assim, essas ações impõem ao indivíduo a responsabilidade de mudar seus hábitos. Esse argumento, no entanto, é sustentado pelo aspecto utilitarista (econômico) de tornar a saúde menos custosa para o Estado, com menos tratamentos, diagnósticos e exames relacionados à obesidade.

Observemos em uma das reportagem analisadas como, por outro lado, ocorre a culpabilização do indivíduo no sistema atual:

Emagrecer demanda uma única providência básica: ter disciplina para comer pouco e fazer exercícios. Mesmo assim, uma multidão acima do peso continua firme atrás do milagre de entrar em forma sem fazer nenhuma dessas coisas (SINATURA, 2010, P. 97).

Nesse sentido, há indivíduos que buscam esse milagre, mesmo sob o risco de estarem utilizando-se de produtos não legalizados ou sem procedência confiável. A mesma revista que estimula a busca e o culto ao corpo perfeito, denuncia: "Dispara a venda ilegal na Internet de remédios para emagrecer, ganhar músculos (...) " (COURA, 2010, P. 124). Cabe considerar, no entanto, que a própria revista Veja estimula nos indivíduos essa busca do corpo perfeito a qualquer custo.

Pensar a Prática, Goiânia, v. 17, n. 2, p. 503-516, jan./mar. 2014 510 
Entendemos que esta noção atual de corpo perfeito foi construída culturalmente e que, dentre várias contribuições para isso, destacam-se a mídia e seus múltiplos artefatos. A mesma promove uma mediação até os potenciais consumidores, e age de forma persuasiva para influenciar pessoas a adotarem atitudes e comportamentos arriscados e impensados na busca pelo corpo saudável, magro e malhado. Nas palavras de Pires:

Numa sociedade que se funda fortemente no valor da imagem, esse apelo à estética constitui objetivo muito buscado e, logicamente, pouco conseguido, o que acaba por revelar-se outra grande contradição, pois a frustração decorrente das dificuldades em adequar-se ao padrão corporal social gera insatisfação e falta de aderência a programas de atividade física, enfim, um resultado bastante diverso daquele preconizado pela anunciada relação exercício físico/beleza/saúde. (2005, p. 38).

Nesse sentido, o excesso de informações, imagens e palavras veiculadas pela mídia reforçam o discurso que saúde e beleza estão interligadas na busca por um corpo perfeito, e podem ser alcançadas via consumo: "Diante da concorrência, até meninos que estão entrando na adolescência (tradução: magrelos e meio desajeitados) apelaram: deixaram a proverbial preguiça de lado e foram para a academia" (VILLAVERDE, 2010b, P. 126).

No trecho da reportagem acima, verifica-se, por exemplo, a não-linearidade no processo comercial e de mediação ideológica, porque existe uma disparidade quando se determina a magreza como exemplo de saúde e, consequentemente, a gordura como sinônimo de doença. Na perspectiva exposta pela revista, existe um padrão que não combina com a obesidade, mas difere da magreza, e ambos precisam do consumo para a correção de seus problemas corporais visando a inclusão social.

A revista Veja apresenta ao público um padrão ideal de beleza que é associado ao sucesso e à felicidade. Essa ideia colabora para o convencimento das pessoas a seguir o padrão de beleza estipulado pela sociedade para não serem rejeitadas: "Antes cobiçado por adultos, o abdômen trincado agora é meta de adolescentes, que fazem ginástica todo dia para conquistar o seu." (VILLAVERDE, 2010b, P. 126).

Para Marx e Engels (2007), no sistema capitalista o consumo parece ideologicamente uma obrigatoriedade. Indivíduos, ao serem expostos aos anúncios são induzidos ao consumo de determinado produto ou serviço. Assim, as empresas capitalistas produzem imagens consideradas ideais para que os consumidores queiram comprar estes determinados produtos: "O McDonald's não pensa só no que seus filhos querem. Pensa no que você quer para seus filhos" (anúncio extraído da revista Veja, ed.2146, p. 14).

Os meios de comunicação de massa têm sido um dos principais responsáveis por expandir essa ideologia do consumo, e tentam determinar qual a melhor maneira para agirmos e definirmos nossa concepção de mundo.

Pensar a Prática, Goiânia, v. 17, n. 2, p. 503-516, jan./mar. 2014 
Como explica Chauí (2000), a alienação social é o desconhecimento das condições histórico-sociais nas quais vivemos, que foram produzidas pela ação humana também sob o peso de outras condições históricas anteriores e determinadas. Dessa forma, por intermédio da alienação, surgem explicações e justificativas para a realidade, como a ideia de que vivemos em uma sociedade com igualdade de oportunidades.

Em uma sociedade capitalista com desigualdades, infelizmente o "sucesso" não é possível para todos. Por outro lado, os grandes empresários circulam mercadorias e investem em propagandas e slogans que promovam de maneira generalizada o produto comercializado. O objetivo primordial da produção e distribuição dessas mercadorias, no entanto, é o lucro, conforme a própria revista VEJA mostra em uma entrevista, embora também veicule propagandas de produtos desse tipo:

O problema é que a indústria segue uma lógica de mercado: tem que ter o menor preço e obter o maior lucro possível. Ou seja, vender muito. Para isso, ela usa matéria prima ruim, enche os alimentos de sal, açúcar ou produtos químicos para realçar o sabor (POLLAN, 2010, P. 178).

O que não se observa na reportagem são análises como: do mesmo modo que as indústrias usam matéria prima ruim para vender produtos, a matéria prima boa encarece o mesmo, estratificando para a elite o seu consumo. Vale considerar, no entanto, o seguinte: tanto os produtos que, em tese, fazem bem para a saúde, quanto o contrário, são mercadorias a serem comercializadas e o seu consumo é estimulado pela sociedade como um todo. Por outro lado, quando se discute obesidade na revista não se questiona a qualidade dos produtos alimentícios oferecidos.

É interessante notar que a mediação ideológica contida nas reportagens analisadas da revista Veja, além de culpabilizar o indivíduo, o tornam responsável pelo controle dos atos e das metas relativas ao amoldamento à sociedade. Observem as seguintes palavras: "As palavras-chave da manutenção do peso são flexibilidade, compensação e controle." (MAGALHÃES, 2010, P. 88). Podemos ser convencidos por ideias. O corpo de ideias constituído se imiscui em nosso pensamento sem, necessariamente, nos darmos conta.

Dessa forma, respaldados na crença de que nossos atos ocorrem de forma plenamente consciente porque somos indivíduos livres, autônomos e que podemos mudar o curso das coisas, como e quando quisermos, a mídia oferta possibilidades para que todos possam alcançar um corpo que se encaixe dentro do padrão de beleza atual. Nesse sentido, criativos anúncios oferecem produtos e serviços prontos para serem consumidos.

$\mathrm{O}$ consumo está ligado à sociedade capitalista, que mercadoriza bens da humanidade e leva as pessoas a sobreporem o consumo na hierarquia das relações sociais. O consumo, por sua vez, é acompanhado por uma perda de autenticidade e de profundidade das pessoas, caracterizada por uma relação irracional com a cultura material. (CHAUÍ, 2000).

Pensar a Prática, Goiânia, v. 17, n. 2, p. 503-516, jan./mar. 2014 


\title{
Considerações Finais
}

$\mathrm{Na}$ presente pesquisa, abordamos a questão da prevalência da obesidade na sociedade contemporânea, apontando inicialmente uma perspectiva que nos adverte sobre seus riscos, suas consequências e males que acarreta na saúde dos indivíduos. Dentre as causas da obesidade, consideram-se as mudanças dos hábitos de vida da população, principalmente relacionadas ao aumento do sedentarismo e da transição nutricional.

Desse modo, ampliaram-se os estudos de autores que buscam encontrar maneiras de minimizar os índices de obesidade e seus danos sobre o organismo. No entanto, as orientações apresentadas estão diretamente ligadas ao comportamento das pessoas, como: adquirir hábitos saudáveis, fazer exercícios físicos regulares, ter uma alimentação balanceada e saudável. Orientações essas voltadas para se evitar os riscos e combater os efeitos deletérios à saúde.

Assim, lançaram-se responsabilidades na esfera individual. Ou seja, a escolha de deixar de ser obeso depende do estilo de vida adotado pelas pessoas, sem realçar medidas de ordem econômica, política ou social necessárias para iluminar a questão da obesidade.

Com base nas premissas apresentadas ao longo do trabalho, cabe afirmar que a mídia analisada - a revista Veja - dada a sua tiragem, a forma e o conteúdo das reportagens trazidas, produz uma mediação ideológica para agregar novos valores ao corpo. Nesses termos, os detentores do poder da informação extraem da realidade o que lhes é útil para compor argumentação baseada em conceitos distorcidos, com vistas a alcançar, a médio ou longo prazo, os seus interesses.

Conforme vimos em Marx e Engels, (2007), a ideologia é um fenômeno complexo que privilegia a aparência e não a essência do fenômeno. Ela encobre e/ou dificulta o conhecimento da realidade social, não nos deixando vê-la como está sendo no processo real e concreto. A função principal da ideologia é ocultar e dissimular as divisões sociais e políticas, dando-lhes a aparência de diferenças naturais entre os seres humanos. Ou seja, apesar da divisão social de classes, somos levados a crer que as desigualdades sociais e econômicas são produzidas por diferenças individuais das capacidades, da inteligência, e da força de vontade de cada um de nós.

Nesse sentido, a mediação ideológica, em certa medida, retira a humanidade desses sujeitos. Dito de outro modo, o fato de alguém ser obeso é motivo suficiente para que seja apresentado como inferior ou incapaz.

\section{THE CONCEPTION OF OBESITY AND STANDARD BODY IN MEDIATIONS IDEOLOGICAL MEDIA}

\begin{abstract}
The obesity in contrast to the establishment of a body pattern is present social issue, discussed, among others, in the area of Physical Education. In this survey it is conveyed as this issue of obesity and body pattern by the media related to the ideological elements contained in the
\end{abstract}

Pensar a Prática, Goiânia, v. 17, n. 2, p. 503-516, jan./mar. 2014 
consumer society. For analysis, was elected the reporting period of one year of a weekly magazine with a circulation of more than one million copies. The results showed that the media can influence to a conception of obesity and body pattern as an end in itself, blaming the individual through the mediation of ideology. In this sense, intertwined health, beauty and profit, consumerism tying product to the pursuit of a perfect body and standardized socially.

Keywords: Obesity. Social Behavior. Media.

\section{LA CONCEPCIÓN DE LA OBESIDAD Y EL CUERPO NORMA EM MEDIACIONES MEDIA IDEOLÓGICOS}

\section{Resumen}

La obesidad en contraste con el establecimiento de un patrón de cuerpo está presente asunto social, discutido, entre otros, en el área de Educación Física. En esta encuesta se transporta ya que esta cuestión de la obesidad y el patrón corporal los medios de comunicación relacionados con los elementos ideológicos contenidos en la sociedad de consumo. Para el análisis, se eligió el período de referencia de un año de una revista semanal con una circulación de más de un millón de copias. Los resultados mostraron que los medios de comunicación pueden influir a una concepción de la obesidad y el patrón del cuerpo como un fin en sí mismo, culpando a la persona a través de la mediación de la ideología. En este sentido, el entrelazado de la salud, la belleza y el beneficio, el consumismo producto vinculante a la búsqueda de un cuerpo perfecto y estandarizado socialmente.

Palabras-claves: Obesidad. Conducta Social. Médios de Comunicación.

\section{Referências}

AL-ASSAL, K. As Loucuras que as pessoas fazem para Emagrecer. In: Revista: VEJA, edição: 2192, 24/novembro/ 2010, p. 165-208.

ALLISON, D.B. SAUNDERS S,E. Obesidad en Estados Unidos. Perspectiva. Medical Clínics on North America. Am 2000 ( 2): 309-334.

BAGRICHEVSKY, M; PALMA, A. Questionamentos e incertezas acerca do estatuto científico da saúde: um debate necessário na educação física. Revista Brasileira de Ciências do Esporte, Campinas, v. 30, n. 2, p. 107-122, jan. 2004.

BRASIL. Ministério da Saúde. Agita Brasil: guia para agentes multiplicadores. Brasília, 2001.

CHAUÍ, M. Convite à Filosofia. São Paulo, Ed. Ática, 2000.

COURA, K. Perigo.com. In: Revista: VEJA, edição: 2155, 10/março/ 2010, p. 124-128.

FELIPPE, F; SANTOS, A.M - Revista da ADPPUCRS, Porto Alegre, 2004.

Pensar a Prática, Goiânia, v. 17, n. 2, p. 503-516, jan./mar. 2014 
FELIPPE, F.M.L., et al. Obesidade e mídia: o lado sutil da informação. Revista Acadêmica do Grupo Comunicacional de São Bernardo. São Bernardo, ano 1, n.2, jul./dez. 2004.

GIL, A. C. Métodos e técnicas de pesquisa social. São Paulo: Atlas, 2008.

ISAPS: The International Society Of Aesthetic Plastic Surgery, www.isaps.org/ - acesso em agosto de 2010.

LESSA, I. Epidemiologia das doenças crônicas não transmissíveis: o adulto brasileiro e as doenças da modernidade. São Paulo: Abrasco, 1998.

MARX, K; ENGELS, F. A Ideologia Alemã. São Paulo: Hucitec, 1986.

MAGAlHAES, N. Como perder e (atenção) Manter o Peso. In: Revista VEJA, edição: 2152, 17/fevereiro/2010, p. 82-91.

MOHERDAUI, B; SINATURA, C. Curvas à Vista. In: Revista: VEJA, edição: 2170, 13/junho/2010a, p. 112-114.

26/maio/2010b, p. 134-138.

O McDonald's não pensa só no que seus filhos querem. Pensa no que você quer para os seus filhos. Anúncio. Revista Veja, ed.2146, 6/jan/2010, p. 14.

OMS. Organização Mundial de Saúde. 2006. Disponível em http://www.who.int/en/. Acesso em: 06 de julho. 2010.

PILATTI, L. A. Tempo e capitalismo: elementos estruturais do esporte moderno. Revista Digital - Buenos Aires - Ano 12 - No 109 - Junho de 2007. Acessado em: 12/01/2008.

PIRES, G. de L. Educação Física e o Discurso Midático: abordagem críticoemancipatória. Ijuí: Unijuí, 2005.

POLLAN, M. Comer é um Ato Social (Entrevista). In: Revista: VEJA, edição: 2192, 24/novembro/ 2010, p. 178.

SBCP: Sociedade Brasileira de Cirurgia Plástica. www.cirurgiaplastica.org.br. Acesso em agosto de 2010. 
SCHWIER, J. Midiatização do Esporte. In: MALINA, A.; CESARIO, S. Esporte: fator de integração e inclusão social? Campo Grande: UFMS, p. 141-156, 2013.

SERRA, G. M. A; SANTOS, E. M. Saúde e mídia na construção da obesidade e do corpo perfeito Ciência \& Saúde Coletiva, 8(3):691-701, 2003.

SILVA A. J.; NETO J. T. M.; RAPOSO J. J. V.; CARVALHAL M. I. M. Obesidade Infantil. Montes Claros: Editora CGB Artes Gráficas, 2007.

SILVA, L. de C. Programa de Modificação do Comportamento Alimentar de Idosos obesos. Dissertação de Mestrado em psicologia clínica. PUC - Campinas, 2002.

SINATURA, C. Esta na Hora da Ração. In: Revista: VEJA, edição: 2156, 17/março/ 2010, p. 97.

SWINBURN, B.; EGGER, G.; RAZA, F. Dissecting obesogenic environments: the development and application of a framework for identifying and prioritizing environmental interventions for obesity. In: Preventive Medicine, [S.1.], n. 29, p. 563$570,1999$.

VILLAVERDE, S. Enxugou tem que Esticar. In: Revista VEJA, edição: 2146, 6/janeiro/ 2010a, p. 84-85.

2010b, p. 126.

É Tanquinho ou não é? In: Revista: VEJA, edição: 2162, 28/abril/

Recebido em: 23/09/2013

Revisado em: 09/12/2013

Aprovado em: 11/12/2013

Endereço para correspondência:

angelaestagio@yahoo.com.br

Mayra Fernanda Vendruscolo

Universidade Federal do Estado do Rio de Janeiro, Escola de Educação Física e Desportos - Dep.

Lutas.

Cidade Universitária

Ilha do Fundão

79000000 - Rio de Janeiro, RJ - Brasil

Pensar a Prática, Goiânia, v. 17, n. 2, p. 503-516, jan./mar. 2014 